\title{
Insights on altered mitochondrial function and dynamics in the pathogenesis of neurodegeneration
}

\author{
Joseph McInnes
}

\begin{abstract}
In neurons, mitochondria are enriched to provide energy and calcium buffering required for synaptic transmission. Additionally, mitochondria localize to the synapse, where they are critical for the mobilization of reserve pool vesicles and for neurotransmitter release. Previously, functional defects in mitochondria were considered to be downstream effects of neurodegenerative diseases. However, more recent findings suggest mitochondria may serve as key mediators in the onset and progression of some types of neurodegeneration. In this review, we explore the possible roles of altered mitochondrial function and dynamics in the pathogenesis of neurodegenerative disorders, with a particular focus on Alzheimer's disease (AD) and Parkinson's disease (PD), which have highlighted the important role of mitochondria in neurodegeneration. While inheritable diseases like Charcot-Marie-Tooth disease type $2 \mathrm{~A}$ are concretely linked to gene mutations affecting mitochondrial function, the cause of mitochondrial dysfunction in primarily sporadic diseases such as AD and PD is less clear. Neuronal death in PD is associated with defects in mitochondrial function and dynamics arising from mutations in proteins affecting these processes, including a-synuclein, DJ-1, LRRK2, Parkin and Pink1. In the case of AD, however, the connection between mitochondria and the onset of neurodegeneration has been less clear. Recent findings, however, have implicated altered function of ER-mitochondria contact sites and amyloid beta- and/or tau-induced defects in mitochondrial function and dynamics in the pathogenesis of $\mathrm{AD}$, suggesting that mitochondrial defects may act as key mediators in the pathogenesis of AD as well. With recent findings at hand, it may be postulated that defects in mitochondrial processes comprise key events in the onset of neurodegeneration.
\end{abstract}

Keywords: Mitochondria, Neurodegeneration, Parkinson's, Alzheimer's, Charcot-Marie-Tooth

\section{Introduction}

In addition to providing the large amount of energy required for synaptic communication in the form of adenosine triphosphate (ATP), mitochondria also participate in a wide variety of other neuronal processes including calcium buffering, intracellular signaling, lipid flux, and mediate contact sites between mitochondria and the endoplasmic reticulum (ER). New findings have complicated our view of the mitochondrion by the elucidation of new roles for mitochondria in cellular physiology, which extend far beyond the traditional role of ATP synthesis. The growing number of of identified processes in which mitochondria play a role has also led

Correspondence: j.mcinnes@jacobs-university.de

School of Engineering and Science, Research Center MOLIFE-Molecular Life Science, Jacobs University Bremen, Campus Ring 1, 28759 Bremen, Germany to new connections between mitochondrial dysfunction and various pathologies in humans [1].

A variety of factors contribute to mitochondrial health and fitness. Human mitochondrial DNA (mtDNA) encodes 13 proteins, which are essential for the assembly and function of the mitochondrial respiratory complexes. Given the small size of the mtDNA molecule, and its high susceptibility to mutations due to close proximity to reactive oxygen species (ROS, a byproduct of respiration), mtDNA maintenance and repair mechanisms are critical for maintaining mitochondrial function [2]. In neurons, defects in mtDNA damage repair lead to the accumulation of deleterious mutations, resulting in decreased mitochondrial respiratory activity and eventually neuronal death [3]. In addition to mtDNA, the nuclear DNA (nDNA) encodes over 1000 mitochondrial 
proteins, which are required for various metabolic and functional processes. Therefore, nDNA maintenance and repair mechanisms in the nucleus also play an important role in maintaining mitochondrial fitness, as the mutation of nDNA genes encoding mitochondrial proteins can lead to pathology [4].

An important factor contributing to mitochondrial health is the dynamic balance of fission and fusion. Since mitochondria cannot be synthesized de novo, the biogenesis of new mitochondria must begin from existing mitochondria. Mitochondrial fission is the process whereby one mitochondrion physically separates into two independent mitochondrial objects. To carry out fission, the mitochondrial-localized Mff protein recruits the cytosolic dynamin-related Drp1 to the mitochondrial outer membrane [5]. Once recruited to the membrane, Drp1 provides the mechanical force to pinch the membrane to cause fission [6]. Fission is not only important for increasing the number of mitochondria within a cell, but also for the disposal of debris by mitophagy-mediated pathways, and is therefore essential for maintaining mitochondrial fitness $[7,8]$. Mitochondrial stress induces fission, and since mitochondrial dysfunction is concomitant with neuronal death, mitochondrial fragmentation due to excessive fission is a hallmark of some neurodegenerative diseases [9]. Moreover, it has been shown that normal levels of mitochondrial fission are required for the mobilization of synaptic vesicles from reserve pools for release into the synaptic cleft, and neurons deficient in Drp1 fail to maintain normal neurotransmission following stimulation [10].

The opposite process of mitochondrial fission is fusion, whereby two mitochondria physically combine to become one single mitochondrion with a continuous membrane. The GTPases Mfn1, Mfn2 and OPA1 are required for mitochondrial fusion, whereby the mitofusins Mfn1 and Mfn2 facilitate outer membrane fusion and OPA1 facilitates inner membrane fusion [11]. Mitochondria are constantly undergoing fusion and fission at various time points throughout their lifecycle, and this dynamic balance gives rise to the diverse mitochondrial morphology observed in cells [12]. A damaged mitochondrion may be rescued by its fusion with a healthy mitochondrion, thereby promoting health and function of the mitochondrial population to ensure cellular fitness [13].

Recent years of research have elucidated the role of interactions between the ER and mitochondria. ERmitochondrial interactions and contact sites are important for processes including lipid modification and flux $[14,15]$, calcium buffering [16], mitochondrial fission $[17,18]$, and organelle inheritance $[19,20]$. In neurons, ER-mitochondria contact sites are particularly important as sites of calcium buffering, where ER and mitochondria coordinate the release of large amounts of calcium ions into the cytosol for intracellular signaling [21]. Notably, an increased concentration of calcium ions in mitochondria leads to an increase in respiratory complex activity and ATP production, providing an important link between intracellular signaling and mitochondrial respiration [22]. Importantly, ER-mitochondria contact sites mark sites of mitochondrial fission, as they play a role in recruiting Drp1 to Mff receptors, and also provide the initial mechanical force to constrict the membrane [17].

In neurodegeneration, mitochondrial dysfunction leads to widespread disturbances in processes critical for neuronal function, including coordinated calcium signaling and neurotransmitter release at the synapse. Though recent research has revealed more links between defects in specific mitochondrial processes and the progression of neurodegeneration, the exact executors (i.e. that which mediates the onset of pathogenesis and neurodegeneration) and pathomechanisms thereof remain poorly defined. Nonetheless, growing evidence suggests mitochondria play a key role in the execution of neurodegeneration, either due to defects in respiratory function or by interaction with other organelles, such as the ER or cytoskeleton. This review attempts to clarify connections between defects in mitochondrial processes and the execution of neurodegeneration, demonstrating that mitochondria are now entering the spotlight for investigating the pathological basis of neurodegenerative diseases.

\section{Parkinson's disease}

The hallmark characteristic of all adult-onset neurodegenerative disorders is the degeneration or death of neurons. In can be broadly stated that this is due to a breakdown in one or more cellular processes essential for fitness, often involving the loss of quality control and recycling mechanisms such as autophagy and the degradation of aggregated or unfolded proteins. Parkinson's disease (PD) is a devastating neurodegenerative disorder affecting about $4 \%$ of seniors over 80 years old, with an average onset around age 60 [23]. While a small portion of PD cases is inherited or due to other known genetic factors, most cases of PD are sporadic. PD is characterized by death of the dopaminergenic neurons (up to $70 \%$ by the time of death) in the substantia nigra region of the brain. This resulting decrease in dopamine levels leads to motor disorders such as limb tremors, stiffness, slowness of movement, and postural instability. Additionally, there is no definitive test for the clinical diagnosis of PD and current treatment only aims to reduce the severity of symptoms [24].

Initially, the most long-standing hypothesis considered the primary executor of neuronal death in PD to be the formation of $\alpha$-synuclein plaques, composed of 
aggregated and insoluble $\alpha$-synuclein protein in Lewy bodies $[25,26]$. Though it was long believed that $\alpha$-synuclein was the primary executor of PD, mitochondria were brought into the spotlight at the end of the 1990s when mutations in a protein named Parkin were identified in a Japanese PD patient [27]. In coming years, it would be described that Parkin is required for the degradation of poorly functioning mitochondria by mitophagy $[7,28]$. Soon after the discovery of Parkin mutations linked to PD, another key player, the PTENinduced kinase 1 (Pink1), would be identified as mutated in PD patients [29]. Today, it is known that Pink1 acts upstream of Parkin, and that the interaction and/or function of these two proteins is altered in PD patients, commonly resulting from mutations in one or both genes in familial cases of PD [30]. Moreover, recent studies have found that $\alpha$-synuclein itself can localize to mitochondria and modulate their function by downregulating complex I activity in a dose-dependent manner [31], and results in mitochondrial fragmentation upon overexpression by promoting translocation of Drp1 to mitochondria [32].

The wealth of information gained from studying the roles of Pink1 and Parkin in PD has given rise to new hypotheses of how mitochondrial dysfunction may influence the pathogenesis of PD. Evidence suggests that in healthy cells, the Pink1/Parkin pathway may act to control for and clear dysfunctional mitochondria, characterized by high ROS levels and low membrane potential [13]. When a mitochondrion becomes dysfunctional, Pink1 attaches to the outer mitochondrial membrane, where it will recruit Parkin [33]. Upon recruitment of Parkin, mitochondria become ubiquitinated, leading to the induction of mitophagy [7]. Interestingly, the kinase activity of Pink1 does not act on Parkin, suggesting that there are other key mediators of mitochondrial function and quality control, the elucidation of which will likely prove fruitful in understanding and treating PD [34]. Moreover, major mitochondrial defects such as elevated oxidative stress and a $20-30 \%$ decrease in the activity of electron transport chain complexes are characteristic of PD patients [35,36]. Taken together, this data may suggest that in the case of PD, mutations in Pink1 and/or Parkin prevent the clearance of dysfunctional mitochondria; because mitochondrial function is critical for providing energy to the cell as well as for synaptic communication, this would ultimately lead to neuronal death.

It is important to note, however, that experiments investigating the role of Pink1/Parkin as possible mediators of mitochondrial function in PD have been limited by their cellular models. Notably, investigations into the possible functions of the Pink1/Parkin system in maintaining cellular fitness have been limited to cultured cells treated with the mitochondrial-uncoupling compound carbonyl cyanide $m$-chlorophenylhydrazone (CCCP), and there is currently little concrete evidence that the Pink1/ Parkin pathway is active in healthy cells. Therefore, how mitochondrial fitness, the Pink1/Parkin pathway, and the onset of neurodegeneration in PD relate to one another in vivo remains to be concretely defined. Additionally, experiments using different model organisms have concluded with inconsistent results as to how mutations in Pink1 and/or Parkin may influence mitochondrial dynamics. In particular, while studies in Drosophila have shown that Pink1 deficiency leads to swollen, perinuclear mitochondria [37,38], Pink1 deficiency in mammalian cells leads to mitochondrial fragmentation $[39,40]$. Thus, the exact mechanism how Pink1 influences mitochondrial dynamics in humans remains undefined; nonetheless, it is evident that Parkin and Pink1 play an important role in regulating mitochondrial fission and fusion, and that this may contribute to overall neuronal fitness.

In addition to $\alpha$-synuclein, Parkin and Pink1, mutated forms of the proteins DJ-1 and LRRK2, as are found in specific forms of familial PD, have also recently been implicated as modifiers of mitochondrial dynamics. Mutations in the leucine-rich repeat kinase 2 (LRRK2) are commonly found in both familial (autosomal-dominant) and sporadic cases of PD. LRRK2 is a large multidomain protein kinase of unknown function, which localizes to the cytosol and associates with the mitochondrial outer membrane [41]. Recent data has shown that overexpression of wild-type LRRK2, as well as the expression of mutated LRRK2 isoforms present in autosomal-dominant PD patients, lead to mitochondrial fragmentation by direct interaction with Drp1 [42]. Moreover, mutations in the DJ-1 protein, as found in cases of autosomal-recessive PD, result in increased Drp1 levels and increased mitochondrial fragmentation [43]. Thus, altered mitochondrial dynamics, and in particular mitochondrial fragmentation, is a notable characteristic in many forms of PD.

In summary, PD pathogenesis has been closely associated with defects in mitophagy and altered mitochondrial dynamics, and it is likely a combination of these defects which leads to neuronal dysfunction during the pathogenesis of PD. Current avenues of research are focusing on the genetic factors affecting mitochondrial function, as well as modifiers and possible rescue mechanisms thereof. Currently, efforts to develop therapies for treating PD focus on either reducing protein plaques or alleviating mitochondrial dysfunction, for example by inducing expression of mitochondrial neuronal uncoupling proteins [44] or bypassing respiratory complex defects to restore normal ATP production. Further research into the Pink1/Parkin pathway of mitophagy will also likely be fruitful in identifying new proteins involved 
in this pathway, thereby providing new opportunities for therapeutic targets.

\section{Alzheimer's disease}

Like Parkinson's, Alzheimer's disease (AD) is another devastating neurodegenerative disorder, affecting an astounding $\sim 6 \%$ of North Americans and Western Europeans above the age of 60 , and over $25 \%$ above the age of 85 [45]. The majority of $\mathrm{AD}$ cases are sporadic, though an estimated 1-5\% of patients carry genetic mutations that are thought to contribute to the onset of $\mathrm{AD}$. $\mathrm{AD}$ patients present symptoms of dementia, including loss of longterm memory, confusion, mood swings, and loss of language skills [46]. In the case of $\mathrm{AD}$, there are currently multiple well-supported hypotheses as to its causes and executors. The hallmark of AD is the death of neurons in the cortex and hippocampus of the brain, and a single executor of this neuronal death remains elusive [47].

Similar to PD, the formation of protein plaques is characteristic of $\mathrm{AD}$. One hypothesis holds that the aggregation of amyloid $\beta$-peptide (A $\beta$ ) (involved in synaptic formation and repair) into plaques is the executor of $\mathrm{AD}$ [48], which has also been genetically linked to familial AD cases in which mutations in the $A P P$ gene lead to increased amounts of $\mathrm{A} \beta$ [49]. The APP gene encodes the amyloid precursor protein (APP), which is processed by $\alpha-, \beta$ - and/or $\gamma$-secretases to generate $A \beta$. In some $A D$ patients, one or more mutations near or within the $\mathrm{A} \beta$-encoding region of APP increase the affinity of APP for $\beta$ - and $\gamma$-secretase, thereby producing an estimated six-fold increase in $A \beta[50,51]$. Additionally, some mutations within the $A \beta$-encoding region also increase the affinity of $A \beta$ to self-aggregate into plaques, which are neurotoxic [52]. Importantly, $A \beta$ accumulates at mitochondria and inhibits respiratory complex IV, increasing ROS production and thereby increasing the frequency of mtDNA mutations [53]. Moreover, the studies of Wang et al. have found that $A \beta$ itself alters mitochondrial dynamics by regulating the activities of proteins essential for fission and fusion, such as Drp1, which can lead to mitochondrial fragmentation [54-56]. These studies have been further supported by findings that $A \beta$ interacts with Drp1, and that APP leads to widespread defects in mitochondrial biogenesis, transport and synaptic activity [57,58]. As discussed further below, altered mitochondrial dynamics may comprise a key event in $\mathrm{AD}$ pathogenesis.

A second hypothesis has become popular in recent years, which holds that hyperphosphorylation of the microtubule-stabilizing tau protein, sporadically or by genetic mutation [59], leads to its aggregation and therefore the formation of neurofibrillary tangles which act as executors of AD [60,61]. Tau is a microtubule-associated protein, which binds microtubules in an unphosphorylated state and stabilizes them. When mutations in the tau-encoding $M A P T$ gene lead to hyperphosphorylation of tau, there is a two-fold effect. First, hyperphosphorylated tau is more likely to aggregate and form neurotoxic protein plaques, and does so in tauopathies. Second, decreased tau binding to microtubules decreases their stability. Mitochondria are transported to the synapse along the axon on linear microtubules by the action of a kinesin KIF5 motor protein [62], where they are critical for synaptic transmission [63]. Thus, the destabilization of microtubules is likely to affect mitochondrial transport to the axon, and thereby impair synaptic communication.

In the case of $\mathrm{PD}$, recent findings have directly linked some PD-associated mutated genes with defects in mitochondrial function and/or dynamics. However, as mutations in genes relevant to $\mathrm{AD}$ are primarily either in genes encoding APP or tau, the role of mitochondria in the pathogenesis of $\mathrm{AD}$ is less clear. Nonetheless, research in the last year has renewed attention in the role of mitochondria in the pathogenesis of $\mathrm{AD}$ with the findings that mutations in APP and tau may have direct affects on mitochondrial function and dynamics. As mentioned above, the destabilization of microtubules by mutations in MAPT is one way in which mitochondrial transport and synaptic transmission are affected by tau hyperphosphorylation. Most recently, one article reports that overexpression of wild-type tau promotes neurodegeneration in Drosophila by blocking mitochondrial localization of Drp1, leading to elongated and dysfunctional mitochondria, and causing neurotoxicity [64]. Though overexpression of wild-type tau is not directly associated with $\mathrm{AD}$ pathogenesis, this provides important evidence that tau itself may directly or indirectly influence mitochondrial dynamics both in healthy neurons as well as in $\mathrm{AD}$ pathogenesis [65]. In another study, expression of the Asp421-cleaved tau isoform, characteristic in the early stages of $\mathrm{AD}$ pathogenesis, has been found to lead to mitochondrial fragmentation in rat neurons [66]. Moreover, another article reported that in SY5Y cells, hyperphosphorylated mutant tau decreases respiratory complex I activity, decreases rates of fission and fusion, and makes cells more vulnerable to oxidative stress [67]. Taken together, these findings suggest that $M A P T$ mutations may directly affect mitochondrial function and dynamics, and thereby may constitute a key event in $\mathrm{AD}$ pathogenesis by causing a deficit in respiratory complex activity, and by leading to mitochondrial fragmentation, both of which are characteristic of the breakdown of neuronal fitness and activity.

As described above, ER-mitochondria contact sites are critical for maintaining mitochondrial function as well as a diverse range of other cellular activities. Recently, it was discovered that ER-mitochondria contact sites are enriched in the presenilins PS1 and PS2 [68]. Presenilins 
are aspartyl proteases, which act as the catalytic core in the $\gamma$-secretase complex for the proteolytic processing of APP to A $\beta$ [69]. Mutations in PS1- and PS2-encoding genes have been associated with the overproduction of $\mathrm{A} \beta$ by $\gamma$-secretase and lead to familial AD [70,71]. Interestingly, $\gamma$-secretase activity at ER-mitochondria contact sites was found to be approximately five-fold higher than in the ER or mitochondria alone, and thus ER-mitochondria contacts are primary sites of $A \beta$ production [68]. Moreover, new evidence shows that ER-mitochondrial contact sites exhibit increased activity and communication under conditions of $\mathrm{AD}$, resulting in altered calcium signaling and lipid metabolism in affected cells [72]. These data support a new hypothesis in which mutations in genes encoding APP, PS1 and/or PS2 increase A $\beta$ production by $\gamma$-secretase at ER-mitochondria contact sites, and thereby alter ER and mitochondrial function as the first step in pathogenesis. As mentioned above, $A \beta$ accumulates in mitochondria, where it induces mtDNA mutations and causes decreased respiratory complex activity [53]. Therefore, under this hypothesis, mutations that lead to increased $A \beta$ production would first impair mitochondrial function, thereby affecting cellular calcium and lipid homeostasis, which may have downstream effects leading to increased $A \beta$ and tau aggregation, and ultimately neuronal death [73]. In this scenario, AD-associated mutations directly impair the function of mitochondria and ERmitochondria contact sites leading to downstream effects characteristic of $\mathrm{AD}$, thus establishing mitochondria as executors of $\mathrm{AD}$ pathogenesis.

\section{Other neurodegenerative diseases}

Since the majority of PD and AD cases are sporadic and not inherited, elucidating the role of mitochondria in neurodegeneration has proved difficult from a genetic standpoint. In some cases, it is difficult to identify if alterations in mitochondrial function are causes of neurodegeneration, or downstream effects of other primary executors. However, in other inheritable neurodegenerative diseases the role of mitochondria as executors of neurodegeneration is more clear, particularly those in which mutations directly affect mitochondrial proteins.

Charcot-Marie-Tooth disease (CMTD) type 2A is an early-onset neurodegenerative disorder, in which mitochondrial dysfunction arising from a nDNA mutation encoding a mitochondrial protein is the primary executor in the onset of neuronal death. CMTD patients carry heterozygous mutations in the gene encoding Mfn2, required for mitochondrial outer membrane fusion [74]. The result is the inhibition of fusion, leading to mitochondrial fragmentation and dysfunction [9]. Moreover, it was recently identified that Mfn2 mutations in CMTD also lead to mtDNA depletion, leading to respiratory complex deficiencies and metabolic dysfunction [75].
Together, this combination of excessive mitochondrial fragmentation and mtDNA depletion lead to severe mitochondrial dysfunction and ultimately the death of peripheral nerves.

Mitochondrial dysfunction associated with inheritable nDNA or mtDNA mutations, which affect mitochondrial function either directly or indirectly, has been implicated in a number of neurodegenerative diseases. Examples include amyotrophic lateral sclerosis, Huntington's disease, optic atrophy, and spinocerebellar ataxia, the causes of which have been discussed elsewhere [76]. Most recently, mitochondrial dysfunction has been associated with the onset of autism spectrum disorder, providing yet another link between mitochondria and neurological disorders [77].

\section{Conclusion}

Altered mitochondrial function and dynamics are hallmark characteristics of neuronal death. However, whether this dysfunction is a downstream effect of neuropathogenesis, or a key mediator thereof, remains unclear. In the case of PD and CMTD, inheritable disease-associated mutations can directly affect mitochondrial proteins associated with mitochondrial function and dynamics, and therefore provide a more clear genetic linkage between mitochondrial defects and neurodegeneration. In the case of $\mathrm{AD}$, however, the role of mitochondria has been less clear, as mutations carried by AD patients do not directly affect mitochondrial proteins. However, recent findings suggest that mitochondrial dysfunction may precede plaque formation in its pathogenesis, and have implicated $\mathrm{A} \beta$, APP and tau as mediators of mitochondrial function and dynamics, thereby suggesting a link between mitochondrial deficiencies and $\mathrm{AD}$-associated mutations. Taking recent findings into account, alterations in mitochondrial function and dynamics may act as pathomechanisms in neurodegeneration. Therefore, future research should focus on rescuing mitochondrial functional defects, such as respiratory complex activity, as well as restoring the balance of mitochondrial fission and fusion as potential therapeutic targets for neurodegenerative disorders.

\section{Abbreviations \\ Aß: Amyloid $\beta$-peptide; AD: Alzheimer's disease; APP: Amyloid beta precursor protein; ATP: Adenosine triphosphate; CCCP: Carbonyl cyanide m-chlorophenylhydrazone; CMTD: Charcot-Marie-Tooth disease; ER: Endoplasmic reticulum; LRRK2: Leucine-rich repeat kinase 2; mtDNA: Mitochondrial DNA; nDNA: Nuclear DNA; PD: Parkinson's disease; ROS: Reactive oxygen species.}

\section{Competing interests}

The author declares that he has no competing interests.

\section{Acknowledgements}

J.M. thanks Prof. Dr. Klaudia Brix in the department of Cell Biology at Jacobs University Bremen for her support and input on this manuscript. 
Received: 6 March 2013 Accepted: 25 May 2013

Published: 27 May 2013

\section{References}

1. Nunnari J, Suomalainen A: Mitochondria: in sickness and in health. Cell 2012, 148:1145-1159.

2. Kazak L, Reyes A, Holt IJ: Minimizing the damage: repair pathways keep mitochondrial DNA intact. Nat Rev Mol Cell Biol 2012, 13:659-671.

3. Yang J-L, Weissman L, Bohr VA, Mattson MP: Mitochondrial DNA damage and repair in neurodegenerative disorders. DNA Repair (Amst) 2008, 7:1110-1120.

4. Zhu X, Peng X, Guan M-X, Yan Q: Pathogenic mutations of nuclear genes associated with mitochondrial disorders. Acta Biochim Biophys Sin 2009, 41:179-187

5. Otera H, Wang C, Cleland MM, Setoguchi K, Yokota S, Youle RJ, Mihara K: Mff is an essential factor for mitochondrial recruitment of Drp1 during mitochondrial fission in mammalian cells. J Cell Biol 2010, 191:1141-1158.

6. Chang C-R, Blackstone C: Dynamic regulation of mitochondrial fission through modification of the dynamin-related protein Drp1. Ann N Y Acad Sci 2010, 1201:34-39.

7. Youle RJ, Narendra DP: Mechanisms of mitophagy. Nat Rev Mol Cell Biol 2011, 12:9-14

8. Ding W-X, Yin X-M: Mitophagy: mechanisms, pathophysiological roles, and analysis. Biol Chem 2012, 393:547-564.

9. Knott $A B$, Perkins $G$, Schwarzenbacher R, Bossy-Wetzel E: Mitochondrial fragmentation in neurodegeneration. Nat Rev Neurosci 2008, 9:505-518.

10. Verstreken P, Ly CV, Venken KJT, Koh T-W, Zhou Y, Bellen HJ: Synaptic mitochondria are critical for mobilization of reserve pool vesicles at Drosophila neuromuscular junctions. Neuron 2005, 47:365-378.

11. Chan DC: Fusion and fission: interlinked processes critical for mitochondrial health. Annu Rev Genet 2012, 46:265-287.

12. Westermann B: Mitochondrial fusion and fission in cell life and death. Nat Rev Mol Cell Biol 2010, 11:872-884

13. Youle RJ, van der Bliek AM: Mitochondrial fission, fusion, and stress. Science 2012, 337:1062-1065.

14. van Meer G, Voelker DR, Feigenson GW: Membrane lipids: where they are and how they behave. Nat Rev Mol Cell Biol 2008, 9:112-124.

15. Osman C, Voelker DR, Langer T: Making heads or tails of phospholipids in mitochondria. J Cell Biol 2011, 192:7-16.

16. Rizzuto R, Pinton P, Carrington W, Fay FS, Fogarty KE, Lifshitz LM, Tuft RA, Pozzan T: Close contacts with the endoplasmic reticulum as determinants of mitochondrial Ca2+ responses. Science 1998, 280:1763-1766.

17. Friedman JR, Lackner LL, West M, DiBenedetto JR, Nunnari J, Voeltz GK: ER tubules mark sites of mitochondrial division. Science 2011, 334:358-362.

18. Rowland AA, Voeltz GK: Endoplasmic reticulum-mitochondria contacts: function of the junction. Nat Rev Mol Cell Biol 2012, 13:607-625.

19. Swayne TC, Zhou C, Boldogh IR, Charalel JK, McFaline-Figueroa JR, Thoms S, Yang C, Leung G, Mclnnes J, Erdmann R, Pon LA: Role for cER and Mmr1p in anchorage of mitochondria at sites of polarized surface growth in budding yeast. Curr Biol 2011, 21:1994-1999.

20. Kornmann B: The molecular hug between the ER and the mitochondria. Curr Opin Cell Biol 2013, 25. In press.

21. Lebiedzinska M, Szabadkai G, Jones AWE, Duszynski J, Wieckowski MR: Interactions between the endoplasmic reticulum, mitochondria, plasma membrane and other subcellular organelles. Int J Biochem Cell Biol 2009, 41:1805-1816

22. Bakowski D, Nelson C, Parekh AB: Endoplasmic reticulum-mitochondria coupling: local $\mathrm{Ca}^{2+}$ signalling with functional consequences. Pflugers Arch 2012, 464:27-32.

23. de Lau LML, Breteler M: Epidemiology of Parkinson's disease. The Lancet Neurology 2006, 5:525-535.

24. Hickey P, Stacy M: Available and emerging treatments for Parkinson's disease: a review. Drug Des Devel Ther 2011, 5:241-254

25. Recchia A, Debetto P, Negro A, Guidolin D, Skaper SD, Giusti P: Alphasynuclein and Parkinson's disease. FASEB J 2004, 18:617-626.

26. Obeso JA, Rodriquez-Oroz MC, Goetz CG, Marin C, Kordower JH, Rodriguez M, Hirsch EC, Farrer M, Schapira AHV, Halliday G: Missing pieces in the Parkinson's disease puzzle. Nat Med 2010, 16:653-661.

27. Kitada T, Asakawa S, Hattori N, Matsumine H, Yamamura Y, Minoshima S, Yokochi M, Mizuno Y, Shimizu N: Mutations in the parkin gene cause autosomal recessive juvenile parkinsonism. Nature 1998, 392:605-608.
28. Greene JC, Whitworth AJ, Kuo I, Andrews LA, Feany MB, Pallanck LJ: Mitochondrial pathology and apoptotic muscle degeneration in Drosophila parkin mutants. Proc Natl Acad Sci USA 2003, 100:4078-4083.

29. Valente EM, Abou-Sleiman PM, Caputo V, Muqit MMK, Harvey K, Gispert S, Ali Z, Del Turco D, Bentivoglio AR, Healy DG, Albanese A, Nussbaum R, González-Maldonado R, Deller T, Salvi S, Cortelli P, Gilks WP, Latchman DS, Harvey RJ, Dallapiccola B, Auburger G, Wood NW: Hereditary early-onset Parkinson's disease caused by mutations in PINK1. Science 2004, 304:1158-1160.

30. Park J, Lee SB, Lee S, Kim Y, Song S, Kim S, Bae E, Kim J, Shong M, Kim J-M Chung J: Mitochondrial dysfunction in Drosophila PINK1 mutants is complemented by parkin. Nature 2006, 441:1157-1161.

31. Liu G, Zhang C, Yin J, Li X, Cheng F, Li Y, Yang H, Uéda K, Chan P, Yu S: alpha-Synuclein is differentially expressed in mitochondria from different rat brain regions and dose-dependently down-regulates complex I activity. Neurosci Lett 2009, 454:187-192

32. Gui $Y-X$, Wang $X-Y$, Kang W-Y, Zhang Y-J, Zhang Y, Zhou Y, Quinn TJ, Liu J, Chen S-D: Extracellular signal-regulated kinase is involved in alphasynuclein-induced mitochondrial dynamic disorders by regulating dynamin-like protein 1. Neurobiol Aging 2012, 33:2841-2854.

33. Narendra DP, Jin SM, Tanaka A, Suen D-F, Gautier CA, Shen J, Cookson MR, Youle RJ: PINK1 is selectively stabilized on impaired mitochondria to activate Parkin. PLoS Biol 2010, 8:e1000298.

34. Abeliovich A: Parkinson's disease: Mitochondrial damage control. Nature 2010, 463:744-745.

35. Schapira AHV: Mitochondrial dysfunction in Parkinson's disease. Cell Death Differ 2007, 14:1261-1266.

36. Hauser DN, Hastings TG: Mitochondrial dysfunction and oxidative stress in Parkinson's disease and monogenic parkinsonism. Neurobiol Dis 2013 51:35-42.

37. Yang Y, Ouyang Y, Yang L, Beal MF, McQuibban A, Vogel H, Lu B: Pink1 regulates mitochondrial dynamics through interaction with the fission/ fusion machinery. Proc Natl Acad Sci USA 2008, 105:7070-7075.

38. Poole AC, Thomas RE, Andrews LA, McBride HM, Whitworth AJ, Pallanck LJ: The PINK1/Parkin pathway regulates mitochondrial morphology. Proc Natl Acad Sci USA 2008, 105:1638-1643.

39. Exner N, Treske B, Paquet D, Holmström K, Schiesling C, Gispert S, CarballoCarbajal I, Berg D, Hoepken H-H, Gasser T, Krüger R, Winklhofer KF, Vogel F, Reichert AS, Auburger G, Kahle PJ, Schmid B, Haass C: Loss-of-function of human PINK1 results in mitochondrial pathology and can be rescued by parkin. J Neurosci 2007, 27:12413-12418.

40. Dagda RK, Cherra SJ, Kulich SM, Tandon A, Park D, Chu CT: Loss of PINK1 function promotes mitophagy through effects on oxidative stress and mitochondrial fission. J Biol Chem 2009, 284:13843-13855.

41. Mata IF, Wedemeyer WJ, Farrer MJ, Taylor JP, Gallo KA: LRRK2 in Parkinson's disease: protein domains and functional insights. Trends Neurosci 2006 29:286-293.

42. Wang X, Yan MH, Fujioka H, Liu J, Wilson-Delfosse A, Chen SG, Perry G, Casadesus $G$, Zhu X: LRRK2 regulates mitochondrial dynamics and function through direct interaction with DLP1. Hum Mol Genet 2012, 21:1931-1944

43. Wang X, Petrie TG, Liu Y, Liu J, Fujioka H, Zhu X: Parkinson's diseaseassociated DJ-1 mutations impair mitochondrial dynamics and cause mitochondrial dysfunction. J Neurochem 2012, 121:830-839.

44. Ho PW, Ho JW, Liu H-F, So DH, Tse ZH, Chan K-H, Ramsden DB, Ho S-L: Mitochondrial neuronal uncoupling proteins: a target for potential disease-modification in Parkinson's disease. Trans/ Neurodegener 2012, 1:3.

45. Mayeux R, Stern Y: Epidemiology of Alzheimer disease. Cold Spring Harb Perspect Med 2012, 2:1-18.

46. Jack CR, Albert MS, Knopman DS, McKhann GM, Sperling RA, Carrillo MC, Thies B, Phelps CH: Introduction to the recommendations from the National Institute on Aging-Alzheimer's Association workgroups on diagnostic guidelines for Alzheimer's disease. Alzheimers Dement 2011, 7:257-262.

47. Goedert M, Spillantini MG: A century of Alzheimer's disease. Science 2006 314:777-781.

48. Hardy J, Selkoe DJ: The amyloid hypothesis of Alzheimer's disease: progress and problems on the road to therapeutics. Science 2002, 297:353-356.

49. Rovelet-Lecrux A, Hannequin D, Raux G, Le Meur N, Laquerrière A, Vital A, Dumanchin C, Feuillette S, Brice A, Vercelletto M, Dubas F, Frebourg T, 
Campion D: APP locus duplication causes autosomal dominant earlyonset Alzheimer disease with cerebral amyloid angiopathy. Nat Genet 2006, 38:24-26.

50. Citron M, Oltersdorf T, Haass C, McConlogue L, Hung AY, Seubert P, VigoPelfrey C, Lieberburg I, Selkoe DJ: Mutation of the beta-amyloid precursor protein in familial Alzheimer's disease increases beta-protein production. Nature 1992, 360:672-674.

51. Cai XD, Golde TE, Younkin SG: Release of excess amyloid beta protein from a mutant amyloid beta protein precursor. Science 1993, 259:514-516.

52. Wisniewski T, Ghiso J, Frangione B: Peptides homologous to the amyloid protein of Alzheimer's disease containing a glutamine for glutamic acid substitution have accelerated amyloid fibril formation. Biochem Biophys Res Commun 1991, 180:1528.

53. Manczak M, Anekonda TS, Henson E, Park BS, Quinn J, Reddy PH: Mitochondria are a direct site of A beta accumulation in Alzheimer's disease neurons: implications for free radical generation and oxidative damage in disease progression. Hum Mol Genet 2006, 15:1437-1449.

54. Wang $X$, Su B, Fujioka H, Zhu X: Dynamin-like protein 1 reduction underlies mitochondrial morphology and distribution abnormalities in fibroblasts from sporadic Alzheimer's disease patients. Am J Pathol 2008 173:470-482.

55. Wang X, Su B, Siedlak SL, Moreira PI, Fujioka H, Wang Y, Casadesus G, Zhu X: Amyloid-beta overproduction causes abnormal mitochondrial dynamics via differential modulation of mitochondrial fission/fusion proteins. Proc Natl Acad Sci USA 2008, 105:19318-19323.

56. Wang X, Su B, Lee H-G, Li X, Perry G, Smith MA, Zhu X: Impaired balance of mitochondrial fission and fusion in Alzheimer's disease. J Neurosci 2009, 29:9090-9103.

57. Calkins MJ, Manczak M, Mao P, Shirendeb U, Reddy PH: Impaired mitochondrial biogenesis, defective axonal transport of mitochondria, abnormal mitochondrial dynamics and synaptic degeneration in a mouse model of Alzheimer's disease. Hum Mol Genet 2011, 20:4515-4529.

58. Manczak M, Reddy PH: Abnormal interaction between the mitochondrial fission protein Drp1 and hyperphosphorylated tau in Alzheimer's disease neurons: implications for mitochondrial dysfunction and neuronal damage. Hum Mol Genet 2012, 21:2538-2547.

59. Hutton M, Lendon CL, Rizzu P, Baker M, Froelich S, Houlden H, PickeringBrown S, Chakraverty S, Isaacs A, Grover A, Hackett J, Adamson J, Lincoln S, Dickson D, Davies P, Petersen RC, Stevens M, de Graaff E, Wauters E, van Baren J, Hillebrand M, Joosse M, Kwon JM, Nowotny P, Che LK, Norton J, Morris JC, Reed LA, Trojanowski J, Basun H, et al: Association of missense and 5 '-splice-site mutations in tau with the inherited dementia FTDP-17. Nature 1998, 393:702-705.

60. Goryunov D, Liem RKH: CHIP-ping away at tau. J Clin Invest 2007, 117:590-592.

61. Duan Y, Dong S, Gu F, Hu Y, Zhao Z: Advances in the Pathogenesis of Alzheimer's Disease: Focusing on Tau-Mediated Neurodegeneration. Trans/ Neurodegener 2012, 1:24.

62. Cai Q, Sheng Z-H: Mitochondrial transport and docking in axons. Exp Neurol 2009, 218:257-267.

63. Vos M, Lauwers E, Verstreken P: Synaptic mitochondria in synaptic transmission and organization of vesicle pools in health and disease. Front Synaptic Neurosci 2010, 2:139.

64. DuBoff B, Götz J, Feany MB: Tau promotes neurodegeneration via DRP1 mislocalization in vivo. Neuron 2012, 75:618-632.

65. DuBoff B, Feany M, Götz J: Why size matters - balancing mitochondrial dynamics in Alzheimer's disease. Trends Neurosci 2013. In press.

66. Quintanilla RA, Dolan PJ, Jin YN, Johnson GW: Truncated tau and A $\beta$ cooperatively impair mitochondria in primary neurons. Neurobiol Aging 2012, 33:619. e25-35.

67. Schulz KL, Eckert A, Rhein V, Mai S, Haase W, Reichert AS, Jendrach M, Müller WE, Leuner K: A new link to mitochondrial impairment in tauopathies. Mol Neurobiol 2012, 46:205-216.

68. Area-Gomez E, de Groof AJC, Boldogh I, Bird TD, Gibson GE, Koehler CM, Yu WH, Duff KE, Yaffe MP, Pon LA, Schon EA: Presenilins are enriched in endoplasmic reticulum membranes associated with mitochondria. Am J Pathol 2009, 175:1810-1816.

69. Takasugi N, Tomita T, Hayashi I, Tsuruoka M, Niimura M, Takahashi Y, Thinakaran G, Iwatsubo T: The role of presenilin cofactors in the gamma-secretase complex. Nature 2003, 422:438-441.
70. Citron M, Westaway D, Xia W, Carlson G, Diehl T, Levesque G, JohnsonWood K, Lee M, Seubert P, Davis A, Kholodenko D, Motter R, Sherrington R, Perry B, Yao H, Strome R, Lieberburg I, Rommens J, Kim S, Schenk D, Fraser P, St George Hyslop P, Selkoe DJ: Mutant presenilins of Alzheimer's disease increase production of 42-residue amyloid beta-protein in both transfected cells and transgenic mice. Nat Med 1997, 3:67-72.

71. Tomita T, Maruyama K, Saido TC, Kume H, Shinozaki K, Tokuhiro S, Capell A, Walter J, Grünberg J, Haass C, Iwatsubo T, Obata K: The presenilin 2 mutation (N141I) linked to familial Alzheimer disease (Volga German families) increases the secretion of amyloid beta protein ending at the 42nd (or 43rd) residue. Proc Natl Acad Sci USA 1997, 94:2025-2030.

72. Area-Gomez E, del Carmen Lara Castillo M, Tambini MD, Guardia-Laguarta C, de Groof AJC, Madra M, Ikenouchi J, Umeda M, Bird TD, Sturley SL, Schon EA: Upregulated function of mitochondria-associated ER membranes in Alzheimer disease. EMBO J 2012, 31:4106-4123.

73. Schon EA, Area-Gomez E: Mitochondria-associated ER membranes in Alzheimer disease. Mol Cell Neurosci 2012, 55:26-36.

74. Züchner S, Mersiyanova IV, Muglia M, Bissar-Tadmouri N, Rochelle J, Dadali EL, Zappia M, Nelis E, Patitucci A, Senderek J, Parman Y, Evgrafov O, Jonghe PD, Takahashi Y, Tsuji S, Pericak-Vance MA, Quattrone A, Battaloglu E, Polyakov AV, Timmerman V, Schröder JM, Vance JM, Battologlu E: Mutations in the mitochondrial GTPase mitofusin 2 cause Charcot-Marie-Tooth neuropathy type 2A. Nat Genet 2004, 36:449-451.

75. Vielhaber S, Debska-Vielhaber G, Peeva V, Schoeler S, Kudin AP, Minin I, Schreiber S, Dengler R, Kollewe K, Zuschratter W, Kornblum C, Zsurka G, Kunz WS: Mitofusin 2 mutations affect mitochondrial function by mitochondrial DNA depletion. Acta Neuropathol 2013, 125:245-256.

76. Schon EA, Przedborski S: Mitochondria: the next (neurode)generation. Neuron 2011, 70:1033-1053.

77. Tang G, Gutierrez Rios P, Kuo S-H, Akman HO, Rosoklija G, Tanji K, Dwork A Schon EA, DiMauro S, Goldman J, Sulzer D: Mitochondrial abnormalities in temporal lobe of autistic brain. Neurobiol Dis 2013, 54:349-361.

doi:10.1186/2047-9158-2-12

Cite this article as: Mclnnes: Insights on altered mitochondrial function and dynamics in the pathogenesis of neurodegeneration. Translational Neurodegeneration 2013 2:12

\section{Submit your next manuscript to BioMed Central and take full advantage of:}

- Convenient online submission

- Thorough peer review

- No space constraints or color figure charges

- Immediate publication on acceptance

- Inclusion in PubMed, CAS, Scopus and Google Scholar

- Research which is freely available for redistribution 